\title{
Physicochemical Characterization of Thermally Treated Chitosans and Chitosans Obtained by Alkaline Deacetylation
}

\author{
Ana Maria de Oliveira, ${ }^{1}$ Telma Teixeira Franco, ${ }^{2}$ and Enio Nazaré de Oliveira Junior ${ }^{1}$ \\ ${ }^{1}$ Department of Chemistry, Biotechnology and Bioprocess Engineering, Federal University of São João Del-Rei, Campus Alto Paraopeba, \\ Ouro Branco 36420-000, MG, Brazil \\ ${ }^{2}$ School of Chemical Engineering, State University of Campinas, Campinas 13083-970, SP, Brazil
}

Correspondence should be addressed to Enio Nazaré de Oliveira Junior; enionazare@yahoo.com.br

Received 13 May 2014; Revised 26 June 2014; Accepted 30 June 2014; Published 22 July 2014

Academic Editor: Long Yu

Copyright (C) 2014 Ana Maria de Oliveira et al. This is an open access article distributed under the Creative Commons Attribution License, which permits unrestricted use, distribution, and reproduction in any medium, provided the original work is properly cited.

\begin{abstract}
The thermal depolymerization of chitosan and alkaline deacetylation of chitin were characterized by measurement of viscosity, gel permeation chromatography (GPC), potentiometric titration (PT), and proton nuclear magnetic resonance spectroscopy $\left({ }^{1} \mathrm{H}\right.$ NMR). The depolymerization rates (DR) measured by kinematic viscosity (KV), apparent viscosity (AV), and GPC (Mw) until $4 \mathrm{~h}$ of treatment were $\mathrm{DR}_{\mathrm{KV}}=21.9, \mathrm{DR}_{\mathrm{AV}}=25.5$, and $\mathrm{DR}_{\mathrm{Mw}}=23.3 \% \mathrm{~h}^{-1}$ and for 5 to $10 \mathrm{~h}$ of treatment they decreased slowly to produce of $\mathrm{DR}_{\mathrm{KV}}=0.545, \mathrm{DR}_{\mathrm{AV}}=0.248$, and $\mathrm{DR}_{\mathrm{Mw}}=1.11 \% \mathrm{~h}^{-1}$. The mole fraction of $\mathrm{N}$-acetylglucosamine residues $\left(F_{\mathrm{A}}\right)$ of chitosans was not modified after $10 \mathrm{~h}$ of thermal treatment at $100^{\circ} \mathrm{C}$. The initial $F_{\mathrm{A}}$ values of chitosan without any treatment were $F_{\mathrm{APT}}=0.21$ and $F_{\mathrm{A}^{1} \mathrm{HNMR}}=0.22$ and of chitosan treated for $10 \mathrm{~h}$ were $F_{\mathrm{APT}}=0.27$ and $F_{\mathrm{A}^{1} \mathrm{HNMR}}=0.22$. The variables used to characterize the depolymerization process showed a good correlation. Six hours of thermal treatment as sufficient to obtain chitosans with a molar mass $90 \%$ smaller than that of the control chitosan without treatment.
\end{abstract}

\section{Introduction}

Chitin, a natural biopolymer, is a structural polysaccharide found in the exoskeleton of marine crustaceans (crab and shrimp shells) and insects. It is also widely found in fungi, such as Basidiomycetes, Ascomycetes, and Phycomycetes, where it is a component of cell walls and structural membranes of mycelia, stalks, and spores. Chitin and chitosan are $\beta$-(1,4)-aminoglucopyranans composed of $\mathrm{N}$-acetylglucosamine $(\mathrm{GlcNAc}=\mathrm{A})$ and glucosamine $(\mathrm{GlcN}=\mathrm{D})$ residues. Chitosan and chitin are polydisperse polymers and the number of their subunits varies. They are distinguished by their solubility in $1 \%$ aqueous acetic acid. Chitin, containing ca. $>40 \%$ GlcNAc residues $\left(F_{\mathrm{A}}>0.4\right)$, is insoluble, whereas soluble polymers are named chitosan (for a review, see $[1,2]$ ).

Several characteristics of chitosan are fundamental in describing the particular molar batch and predicting its chemical and physical properties: the average molar mass of the sample, its average degree of acetylation (DA, given as a percentage) or the fraction of acetylation $\left(F_{\mathrm{A}}\right.$, given as the mole fraction), and the local and global distribution of the acetylated amide moieties along the chain as well as the polydispersity index, the viscosity, and the ash content [1]. Presently, a substantial amount of research is devoted to the application of chitosan and derivatives for antimicrobial purposes against a wide range of phytopathogenic fungi [3-5] and pathogenic bacteria [6].

Chitosan, like other polysaccharides, is susceptible to a variety of degradation mechanisms, including oxidativereductive free radical depolymerization and acid-, alkaline, and enzyme-catalyzed hydrolysis. Degradation of polysaccharides occurs via cleavage of the glycosidic bonds [7]. Several studies have been done to evaluate the acid hydrolysis of chitosan. The acid hydrolysis of chitin was studied for the first time in 1992 by Roberts, who used $\mathrm{HNO}_{3}$ [8]. Different acids have been used in the hydrolysis of chitosan: hydrochloric acid [9-13], phosphoric acid [14, 15], sulfuric acid and acetic anhydride [16], nitrous acid [17], and hydrogen fluoride [18].

Unlike acid hydrolysis, enzymatic hydrolysis of chitin and chitosan by chitinases (EC 3.2.1.14) and chitosanases 
(EC 3.2.1.132) permits the production of different oligomers. Hydrolysis of chitin and chitosan catalyzed by specific chitinase and chitosanase enzymes has been employed in several studies [19-23]. A few studies have been done to evaluate the degradation of chitosan in solid form by thermal treatment [7, 24-29]. Thermal treatment of chitosan is an alternative method to obtain chitosans with small degree of polymerization (DP) and the same $F_{\mathrm{A}}$. The reaction mechanisms of thermal treatment of chitosan have been studied [7, 28, 29]; however they were not completely elucidated.

The aims of this work were to investigate chitosan degradation in solid form by thermal treatment to obtain chitosan with small DP and alkaline deacetylation of chitin. In order to evaluate the extension of these processes, the capability of some analytical methods was further investigated. For molar mass determination two methods were used: viscometry and gel permeation chromatography (with a refractive index detector, GPC). For a determination of the degree of acetylation, potentiometric titration (PT) and high-field ${ }^{1} \mathrm{H}$ NMR spectroscopy were used.

\section{Materials and Methods}

2.1. Raw Materials. Chitosan was supplied by Polymar (Fortaleza, Brazil). Chitin (Sigma Chemical Co. St. Louis, USA) was used in the deacetylation reaction to obtain chitosans with different degrees of acetylation. Dextran standards (American Polymers, Ohio, USA) were used for calibration of GPC columns (Mw: 11, 38, 72, 260, and $530 \mathrm{kDa}$ ). Sodium azide was from Sigma (St. Louis, USA), lactic acid was from Synth (Diadema, Brazil), acetic acid, sodium chloride, urea, hydrochloric acid, and deuterium chloride were from $E$. Merck (Darmstadt, Germany).

2.2. Thermal Depolymerization of Chitosan. Thermal depolymerization was performed by a procedure described in the literature [7], with slight modifications. Solid chitosan (8 g) was placed in $9 \mathrm{~cm}$ glass Petri plates and thermally degraded in an oven at $100^{\circ} \mathrm{C}$ for up to $10 \mathrm{~h}$. At $1 \mathrm{~h}$ intervals, during this treatment, $1.5 \mathrm{~mL}$ of distilled water was added to the chitosan.

2.3. Kinematic and Apparent Viscosities. The thermal depolymerization of all chitosans was analyzed by kinematic and apparent viscosities. Thermally treated chitosans were transferred to lactic acid solution $\left(0.15 \mathrm{~mol} \mathrm{dm}^{-3}\right)$, stirred in an orbital shaker for $3 \mathrm{~h}$, and filtered through a glass sintered filter $\mathrm{n}^{\circ} 4$. Kinematic viscosity (cSt) and apparent viscosity (Pa s) of the filtrate were determined using a Cannon-Fenske $\mathrm{n}^{\circ} 200$ viscometer and a Brookfield Programmable DV-II rheometer at $25 \pm 0.1^{\circ} \mathrm{C}$, respectively, in accordance with the manufacturer's instructions.

2.4. Determination of Average Molar Mass by GPC. The extent of thermal depolymerization of chitosan was assessed by gel permeation chromatography with a refractive index detector (GPC). Heat treated chitosan samples were dissolved $\left(1.0 \mathrm{mg} \mathrm{dm}^{-3}\right)$ in sodium acetate buffer $\left(0.33 \mathrm{~mol} \mathrm{dm}^{-3}\right.$ acetic acid, $\left.0.1 \mathrm{~mol} \mathrm{dm}{ }^{-3} \mathrm{NaOH}, \mathrm{pH}=3.9 \pm 0.2\right)$ and centrifuged
TABLE 1: Chitosan samples used to determine the viscosity average molar masses $(\mathrm{Mv})$.

\begin{tabular}{lccc}
\hline Treatment & Temperature $\left({ }^{\circ} \mathrm{C}\right)$ & Time $(\mathrm{h})$ & Code \\
\hline $\begin{array}{l}\text { Thermally treated } \\
\text { chitosan }\end{array}$ & 100 & 0 (control) & $\mathrm{A}$ \\
& & 3 & $\mathrm{~B}$ \\
\hline $\begin{array}{l}\text { Chitosan obtained by } \\
\text { alkaline deacetylation }\end{array}$ & $100-110$ & 10 & $\mathrm{C}$ \\
of chitin & $110-122$ & 1.5 & $\mathrm{D}$ \\
\hline
\end{tabular}

TABLE 2: Viscosity parameters of chitosans (for references and discussion, see Roberts [8]).

\begin{tabular}{ccccc}
\hline Code & $\mathrm{Mv}\left(\mathrm{g} \mathrm{mol}^{-1}\right)$ & Solvent & $K\left(\mathrm{dm}^{3} / \mathrm{g}\right)$ & $a$ \\
\hline \multirow{3}{*}{1} & $113,000-492,000$ & $\begin{array}{c}0.2 \mathrm{~mol} \mathrm{dm}^{-3} \mathrm{HOAc}, \\
0.1 \mathrm{~mol} \mathrm{dm}^{-3} \mathrm{NaCl},\end{array}$ & $0.893 \times 10^{-4}$ & 0.71 \\
& & $4 \mathrm{~mol} \mathrm{dm}^{-3}$ \\
\multirow{5}{*}{2} & $90,000-1,140,000$ & $0.1 \mathrm{~mol} \mathrm{dm}^{-3} \mathrm{HOAc}$, & $0.181 \times 10^{-5}$ & 0.93 \\
& & $0.2 \mathrm{~mol} \mathrm{dm}^{-3} \mathrm{NaCl}$ \\
3 & $13,000-135,000$ & $0.33 \mathrm{~mol} \mathrm{dm}^{-3} \mathrm{HOAc}$, & $0.341 \times 10^{-5}$ & 1.02 \\
& & $0.3 \mathrm{~mol} \mathrm{dm}^{-3} \mathrm{NaCl}$ & & \\
\hline
\end{tabular}

at $10000 \times \mathrm{g}$ for $60 \mathrm{~s}$. A calibration curve was established with

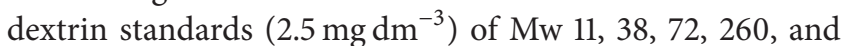
$530 \mathrm{kDa}$ (American Polymers, Mentor, $\mathrm{OH}$, USA) dissolved in water containing $0.05 \%(\mathrm{~m} / \mathrm{v})$ sodium azide. The GPC system (Waters Corporation, Milford, Massachusetts, USA) consisted of a model 515 pump, a model 717 automatic injector, and a 410 differential refractometer, and the data were handled by Waters' Millenium GPC software. Two columns of polymethyl methacrylate hydroxylate (Waters Ultrahydrogel 1000 and Ultrahydrogel 500), with respective exclusion volumes of $1.0 \times 10^{6}$ and $8.0 \times 10^{4} \mathrm{Da}$, were connected in series. The injected sample volume was $200 \mu \mathrm{L}$ and the mobile phase was the same sodium acetate buffer as that used to dissolve the sample, flowing at $0.8 \mathrm{~mL} \mathrm{~min}^{-1}$ with a temperature of $40^{\circ} \mathrm{C}$. The accuracy of GPC method, used to determine the Mw of thermally treated chitosan samples, is $3-4 \%$.

2.5. Determination of Viscosity Average Molar Mass (Mv) of Chitosan. The viscosity average molar mass of the five chitosans described in Table 1 was also determined by intrinsic viscosity [8].

Three different solvents were tested in order to find the most suitable (Table 2 ). $K$ and $a$ are constants that are independent of molar mass over a considerable range of molar masses and depend on the polymer, solvent, temperature, and, in the case of polyelectrolytes, the nature and concentration of the low-molar-mass electrolyte added. The Ubbelohde viscometer was kept at a temperature of $25.0 \pm$ $0.1^{\circ} \mathrm{C}$ by means of a water bath. The solvent flow times were preferably longer than $100 \mathrm{~s}$. Chitosan average molar mass was determined using a Ubbelohde viscometer, type 53110/I from Schott GmbH.

In order to select the best solvent, Mv of sample A (raw material) was determined using solvents 1,2 , and 3 , and for samples B, C, D, and E solvent 3 was used. A 0.5\% stock 
solution (w/v) was prepared for each chitosan and the range of concentrations used was 1.0 to $5.0 \mathrm{~g} \mathrm{dm}^{-3}$. When the dissolution was complete, the solution was filtered through a Schott glass sintered filter $n^{\circ} 4$. The correct concentration of dissolved polysaccharide was calculated as the difference between the initial amount of polymer and the insoluble part, using

$$
C=\frac{m_{1}-\left(m_{2}-m_{0}\right)}{v},
$$

where $C$ is the concentration of chitosan solution, $m_{0}$ is the mass of dry filter, $m_{1}$ is the mass of chitosan sample, and $m_{2}$ is the mass of filter containing insoluble particles after drying.

The intrinsic viscosity was determined according to

$$
\left[\eta_{i}\right]=\frac{\left(t_{1}-t_{0}\right) / t_{0}}{c}
$$

where $t_{1}$ is the flow time for the chitosan solution, $t_{0}$ is the flow time for the solvent system, and $\eta_{i}$ is the intrinsic viscosity.

The limiting viscosity number was found by the extrapolation of Mark-Houwink's relationship between the intrinsic viscosity and the concentration of chitosan in the investigated solution to concentration of chitosan of zero.

The average molar mass was obtained according to

$$
\mathrm{Mv}=\left(\frac{\eta_{L}}{K}\right)^{1 / a},
$$

where $\mathrm{Mv}$ is the viscosity average molar mass, $\eta_{L}$ is limiting viscosity number, and $K$ and $a$ are Mark-Houwink constants.

2.6. Alkaline Deacetylation of Chitin. The kinetics of homogeneous alkaline deacetylation of $\alpha$-chitin was reported to be a pseudo-first-order reaction at high temperature (80 to $\left.120^{\circ} \mathrm{C}\right)\left[30\right.$ ] and also at low temperature $\left(-5\right.$ to $\left.-35^{\circ} \mathrm{C}\right)$ [31]. Deacetylation of chitin was achieved in accordance with a modified procedure developed by Canella and Garcia [32]. Sixteen grams of chitin (Sigma Chemical, St. Louis, USA) were suspended in $200 \mathrm{~mL}$ of $50 \% \mathrm{NaOH}$ solution $(\mathrm{m} / \mathrm{v})$ and stirred at $900 \mathrm{rpm}$ in a batch reactor under reflux. In Table 3 the temperatures and times used to obtain samples D and $\mathrm{E}$ are described and a summary of the purification process is given (Table 3 ).

2.7. Determination of the Degree of N-Acetylation by Potentiometric Titration. The mole fraction of N-acetylglucosamine residues $\left(F_{\mathrm{A}}\right)$ was determined using potentiometric titration, as described by Raymond et al. [33]. The 1\% chitosan sample $(\mathrm{w} / \mathrm{v})$ was added to $\mathrm{HCl} 0.1 \mathrm{~mol} \mathrm{dm}^{-3}$ and titrated with a solution of $\mathrm{NaOH} 0.1 \mathrm{~mol} \mathrm{dm}^{-3}$. The neutralization point was determined potentiometrically.

The values of $F_{\mathrm{A}}$ were calculated according to

$$
F_{\mathrm{A}}=1-\frac{V_{\mathrm{NaOH}} \times M_{\mathrm{NaOH}}}{\left(m_{\mathrm{ch}} / M_{\mathrm{ch}}\right)},
$$

where $F_{\mathrm{A}}$ is the mole fraction of $\mathrm{N}$-acetylglucosamine residues, $m_{\mathrm{ch}}$ is the chitosan sample mass, $M_{\mathrm{ch}}$ is the molar
TABLE 3: Conditions of alkaline deacetylation of chitin and purification of chitosan samples.

\begin{tabular}{lcc}
\hline Batch & 1 & 2 \\
\hline Temperature $\left({ }^{\circ} \mathrm{C}\right)$ & $100-110$ & $110-122$ \\
\hline Time (minutes) & 60 & 80 \\
\hline Cooling & Centrifugation $10,000 \mathrm{~g}$ for 5 minutes \\
\hline Washing of pellet until low conductivity is achieved \\
\hline Colubilization in $0.15 \mathrm{dm}^{3} / \mathrm{L}$ lactic acid and orbital shaker at \\
200 opm \\
\hline Obtention of supernatant \\
Neutralization of supernatant with NaOH $1 \mathrm{dm}^{3} / \mathrm{L}$ until \\
pH $=8.5$ is reached
\end{tabular}

mass of glucosamine unit, $V_{\mathrm{NaOH}}$ is the volume of $\mathrm{NaOH}$ $0.1 \mathrm{~mol} \mathrm{dm}^{-3}$ solution used to neutralize the protonated free amino groups, and $M_{\mathrm{NaOH}}$ is the molar concentration of $\mathrm{NaOH}$ solution.

2.8. Determination of the Degree of N-Acetylation by HighField ${ }^{1} H$ NMR Spectroscopy. In accordance with a procedure adapted from a publication by Vårum et al. [34], a sample of roughly $100 \mathrm{mg}$ of chitosan was suspended in $10 \mathrm{~mL}$ of $0.07 \mathrm{~mol} \mathrm{dm}^{-3} \mathrm{HCl}$ at room temperature with stirring overnight. A small mass of $\mathrm{NaNO}_{2}(9-10 \mathrm{mg})$ was added to the stirring solution and left to react for $4 \mathrm{~h}$. The solution was lyophilized and then ion-exchanged with $\mathrm{D}_{2} \mathrm{O}$ three times. The samples were dissolved in roughly $1.5 \mathrm{~mL}$ of $\mathrm{D}_{2} \mathrm{O}$ and filtered through cotton to remove any insoluble mass. ${ }^{1} \mathrm{H}$ NMR spectra of the samples were obtained in a Bruker $300 \mathrm{MHz}$ NMR spectrometer at room temperature after 32 scans with a delay time of 3 to 4 seconds. The degree of acetylation is given by

$$
\mathrm{F}_{\mathrm{A}}=\frac{7\left(\mathrm{I}_{\mathrm{B}}+\mathrm{I}_{\mathrm{E}}\right)}{\left[4\left(\mathrm{I}_{\mathrm{A}}+\mathrm{I}_{\mathrm{C}}+\mathrm{I}_{\mathrm{D}}\right)+\mathrm{I}_{\mathrm{B}}+\mathrm{I}_{\mathrm{E}}\right]},
$$

where I is the peak intensity, represented as an integral, and the subscripts $\mathbf{A}$ to $\mathbf{E}$ identify particular peaks indicated in Figures 4(a) and 4(b). Peaks A and B correspond to the anomeric protons GlcN and GlcNAc, respectively; $\mathbf{C}$ and D correspond to ring protons; $\mathrm{E}$ corresponds to the methyl protons.

2.9. Statistical Analysis. The result of each treatment was the average of two or three repetitions depending on the analysis realized. The results were analyzed by ANOVA and regression at $P \leq 0.05$. The models were selected analyzing the determination coefficients $\left(R^{2}\right)$ and significance of regression coefficients tested by Student's $t$-test. 


\section{Results and Discussion}

3.1. Evaluation of Thermal Depolymerization. The most commonly used methods for determination of $\mathrm{Mv}, \mathrm{Mw}$, and $\mathrm{Mn}$ are viscosity, light scattering (SLS: static light scattering and MALLS: multiple-angle laser light scattering), and GPC (gel permeation chromatography) or SEC (size exclusion chromatography) [35].

Insoluble materials were observed in the raw material from Polymar. Approximately, $1 \%$ of insoluble material was retained on sintered glass filter $n^{\circ} 4$ from $1 \%$ chitosan solution $(\mathrm{m} / \mathrm{v})$ in lactic acid $\left(0.15 \mathrm{~mol} \mathrm{dm}^{-3}\right)$. The formation of insoluble material increased with increase in treatment time. Approximately, $2 \%$ and $6 \%$ of insoluble materials were retained on sinterized glass filter $n^{\circ} 4$ from $1 \%$ chitosan solutions of samples thermally treated for 3 and $10 \mathrm{~h}$, respectively. Some insoluble materials were also observed by Holme et al. [7]. The formation of insoluble material can be explained by interchain cross-link formation involving free amino groups and reducing ends [36].

The thermal degradation of chitosan samples in solid state treated at $100^{\circ} \mathrm{C}$ during $10 \mathrm{~h}$ was analyzed by viscosity (kinematic, intrinsic, and apparent viscosities) and gel permeation chromatography with a refractive index detector (GPC). Values of kinematic and apparent viscosities and molar mass (Mw) are shown in Figures 1(a) and 1(b). The empirical models adjusted to the experimental data of kinematic viscosities (6), apparent viscosities (7), and average molar masses (8) were statistically significant at $P \leq 0.05$. Consider

$$
\begin{gathered}
Y_{\mathrm{KV}}=-0.03373 X^{3}+0.85342 X^{2}-7.05007 X+20.19318, \\
R^{2}=0.99193
\end{gathered}
$$

$$
\begin{gathered}
Y_{\mathrm{AV}}=-0.05609 X^{3}+1.62181 X^{2}-1.10938 X+4.17165, \\
R^{2}=0.96158 \\
Y_{\mathrm{MW}}=4.29172 X^{2}-74.75343 X+323.88758 \\
R^{2}=0.95506 .
\end{gathered}
$$

Values of Mw determined by GPC were calculated using chromatograms and calibration curve for the dextran standard. Both chromatograms and calculation of the calibration curve for the dextran standard were obtained with the software Millenium (for chromatograms and calibration curve, see Figures $1 \mathrm{Sa}$ and $\mathrm{b}$ in Supplementary Material available online at http://dx.doi.org/10.1155/2014/853572). From the chromatographic profiles for control and chitosans treated for up to $10 \mathrm{~h}$ (Figure 2) and calibration curve were obtained the molar mass distribution of chitosan samples and their Mw.

The kinematic and apparent viscosities and molar masses of chitosan samples treated for six h at $100^{\circ} \mathrm{C}$ decreased more than $90 \%$ (Table $1 S$ ). After $10 \mathrm{~h}$ of treatment, decreases in kinematic and apparent viscosities and Mw of the chitosans of $92.0 \%, 96.5 \%$, and $96.7 \%$, respectively, were observed.
Thermal depolymerization of chitosan chloride with different $F_{\mathrm{A}}$ was studied by Holme et al. [7] at different temperatures. The decrease in apparent viscosity obtained for chitosan $F_{\mathrm{A}}=0.35$ treated at $105^{\circ} \mathrm{C}$ for $10 \mathrm{~h}$ was about $90 \%$ [7]. In our study for chitosan $F_{\mathrm{A}}=0.22 \%$ treated at $100^{\circ} \mathrm{C}$ for $10 \mathrm{~h}$, a decrease of $96.5 \%$ in apparent viscosity was observed (Table 1S).

The thermal depolymerization of chitosan occurs in two phases. In the first stage (0-4h of treatment) an increase in chitosan depolymerization, predicted by the linear model, was observed (Figure 3 ) and in the second stage (5-10 h of treatment) a tendency towards process stabilization (Figures 1(a) and 1(b)).

Similar results were observed by viscosity and GPC measurements. In Figure 3 it can be seen that the depolymerization rate increased with time. The depolymerization rates measured by kinematic viscosity, apparent viscosity, and molar mass for $4 \mathrm{~h}$ were $21.9,25.5$, and $23.3 \% \mathrm{~h}^{-1}$, respectively.

It was observed that the depolymerization rates in the period of 5 to $10 \mathrm{~h}$ of treatment decreased slowly, and the values observed were $\mathrm{DR}_{\mathrm{KV}}=0.545, \mathrm{DR}_{\mathrm{AV}}=0.248$, and $\mathrm{DR}_{\mathrm{MW}}=1.11 \% \mathrm{~h}^{-1}$ (for linear regression, see Supplementary Figure 2S).

Viscometry and GPC gave similar results in the analysis of chitosans with a range of molar masses from 235,000 to 43,000 $\mathrm{g} \mathrm{mol}^{-1}$ and polydispersity indices from 7 to 3.5 ; however, in the analysis of chitosans with a range of molar masses from 22,000 to $8,000 \mathrm{~g} \mathrm{~mol}^{-1}$ and polydispersity indices from 2.3 to 1.3 the methods gave different results. This difference may be related to the hydrodynamic volume of the macromolecules, which is a function of molar mass, conformational properties, and polymer-solvent interactions, as described by Terbojevich and Cosani [35].

Table $1 \mathrm{~S}$ shows the decrease in the values of kinematic and apparent viscosities and molar mass as measured by viscometry and GPC. Each parameter had significantly different values for the decrease up to $t_{\mathrm{KV}}=7 \mathrm{~h}, t_{\mathrm{AV}}=4 \mathrm{~h}$, and $t_{\mathrm{Mw}}=6 \mathrm{~h}$. Chitosans thermally treated at $100^{\circ} \mathrm{C}$ for 8,9 , and $10 \mathrm{~h}$ did not show a significant decrease in AV and Mw. The degradation of chitosan in the first $4 \mathrm{~h}$ of thermal treatment, measured by KV, AV, and GPC, was significant $(P \leq 0.05)$.

In our work, two depolymerization rates were found, the first one for up to $4 \mathrm{~h}$ of heating $\left(\mathrm{DR}_{\mathrm{KV}}=21.9, \mathrm{DR}_{\mathrm{AV}}=25.5\right.$, and $\left.\mathrm{DR}_{\mathrm{Mw}}=23.3 \% \mathrm{~h}^{-1}\right)$ and the lower rate $\left(\mathrm{DR}_{\mathrm{KV}}=0.545\right.$, $\mathrm{DR}_{\mathrm{AV}}=0.248$, and $\mathrm{DR}_{\mathrm{Mw}}=1.11 \% \mathrm{~h}^{-1}$ ) for the treatment time interval from 5 to $10 \mathrm{~h}$, when a decrease in molar mass of more than $90 \%$ had already been achieved. Three techniques used to evaluate the thermal depolymerization process had linear relationships $(P \leq 0.05)$ in the treatment time interval up to $4 \mathrm{~h}$; that is, the slope of the linear regression line predicts the depolymerization rate (DR) of chitosan treated thermally in a specific time interval. Analysis of thermal depolymerization kinetics of chitosans based on the KV, AV, and Mw data showed good agreement with DR values that did not vary statistically at $P \leq 0.05$. The viscosities and the average molar masses had a statistical tendency to become stable from $5 \mathrm{~h}$ on, and further heating did not seem to cause further chitosan depolymerization. 


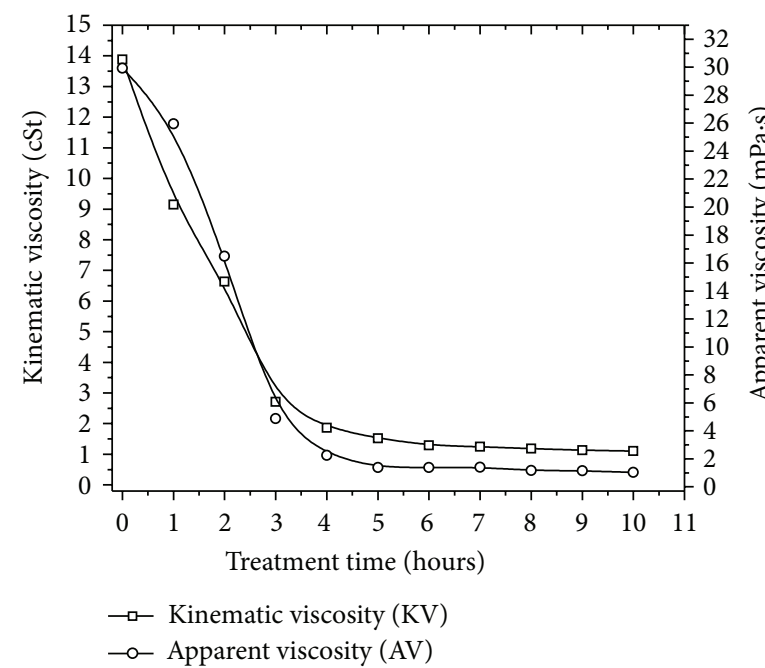

(a)

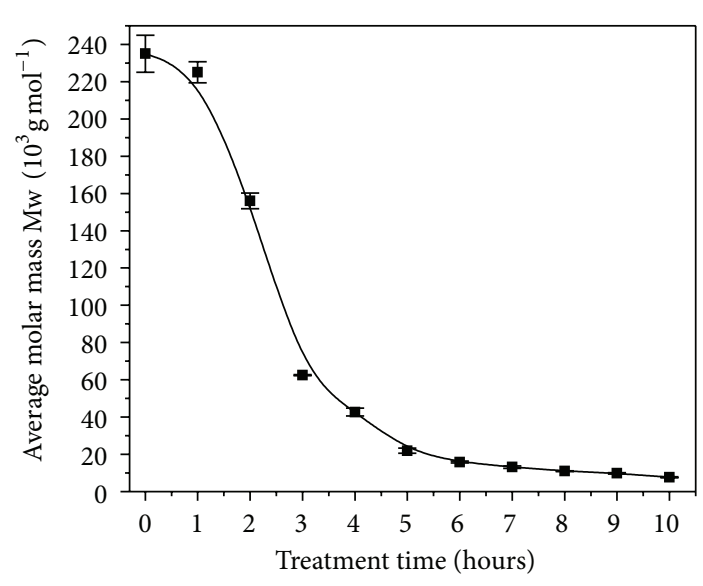

(b)

FIGURE 1: Kinematic and apparent viscosities (a) and average molar mass (b) of chitosans in solid state thermally degraded at $100^{\circ} \mathrm{C}$ for up to $10 \mathrm{~h}$.

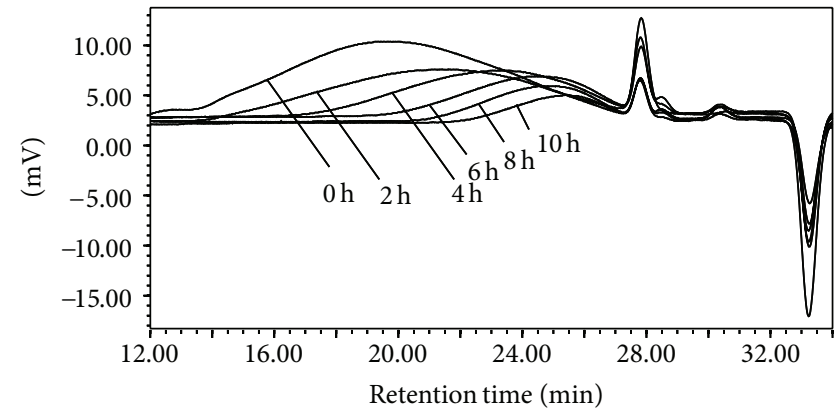

FIGURE 2: Chromatographic profiles obtained by GPC for control chitosan without thermal treatment ( 0 hour) and chitosans treated for up to $10 \mathrm{~h}$.

The mechanism of thermal degradation of chitosan was studied by Holme et al. [7]. The oxidative-reductive degradation mechanism was discarded after it was confirmed that thermal degradation with and without oxygen (nitrogen atmosphere) did not affect the degradation rate. Chitosan chloride in solid state $F_{\mathrm{A}}=0.16$ with $\mathrm{pH} 4,5$, and 6 was thermally treated at $105^{\circ} \mathrm{C}$ and an increase in thermal degradation with the increase in $\mathrm{H}^{+}$concentration was observed. It was confirmed that acid hydrolysis is the primary mechanism of the thermal degradation of chitosan chloride. Acid hydrolysis of the glycosidic linkages involves both protonation of the glycosidic oxygen and addition of water to yield the reducing sugar end group [37]. Zawadzki and Kaczmarek [28] studied the changes of chitosan structure during storage in vacuum or in oxygen atmosphere at room and elevated temperatures (up to $600^{\circ} \mathrm{C}$ ) using FTIR spectroscopy and thermogravimetry. They observed that gradual increase of temperature (20$150^{\circ} \mathrm{C}$ ) and regulation of heating time allow for the complete dehydration without destruction of the chitosan chemical

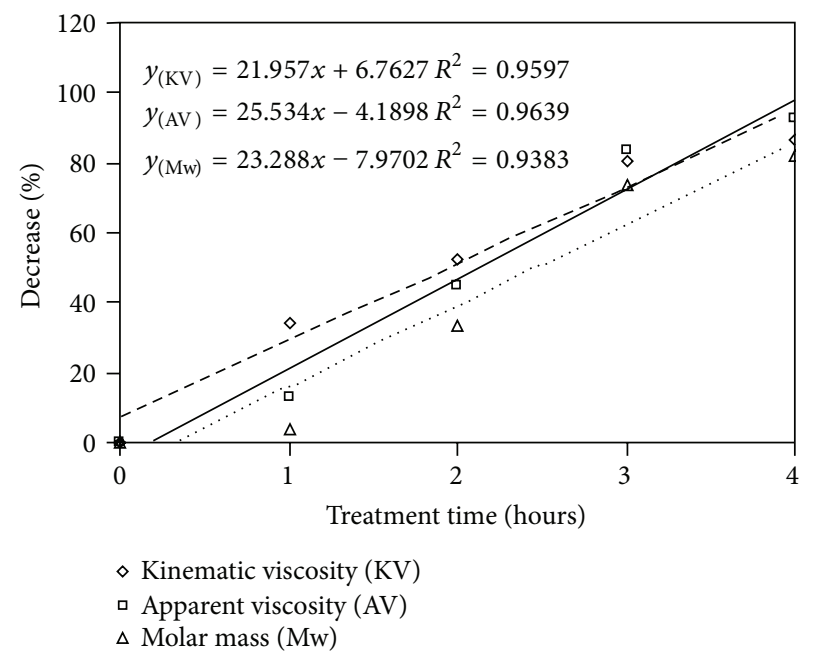

FIGURE 3: Decrease in kinematic and apparent viscosities and molar masses of chitosans in solid state thermally degraded at $100^{\circ} \mathrm{C}$ for $4 \mathrm{~h}$ $(P \leq 0.05)$.

structure in vacuum and $F_{\mathrm{A}}$ remained constant on this range of temperature.

In our study chitosan in solid state was used with the addition of water at time intervals of 1 hour to maintain the $\mathrm{H}^{+}$concentration during the heating treatment in oxygen atmosphere at $100^{\circ} \mathrm{C}$ and to hydrolyze the glycosidic linkages. The thermal treatment was carried out at $100^{\circ} \mathrm{C}$ to produce chitosans with different DP and the same $F_{\mathrm{A}}$.

3.2. Determination of Viscosity Average Molar Mass of Chitosan. The Mv of control chitosan (A) was determined using solvent $1\left(0.2 \mathrm{~mol} \mathrm{dm}^{-3}\right.$ of acetic acid, $0.1 \mathrm{~mol} \mathrm{dm}^{-3}$ of sodium chloride, and $4 \mathrm{~mol} \mathrm{dm}^{-3}$ of urea), solvent $2\left(0.1 \mathrm{~mol} \mathrm{dm}^{-3}\right.$ of acetic acid and $0.2 \mathrm{~mol} \mathrm{dm}^{-3}$ of sodium chloride), and solvent 


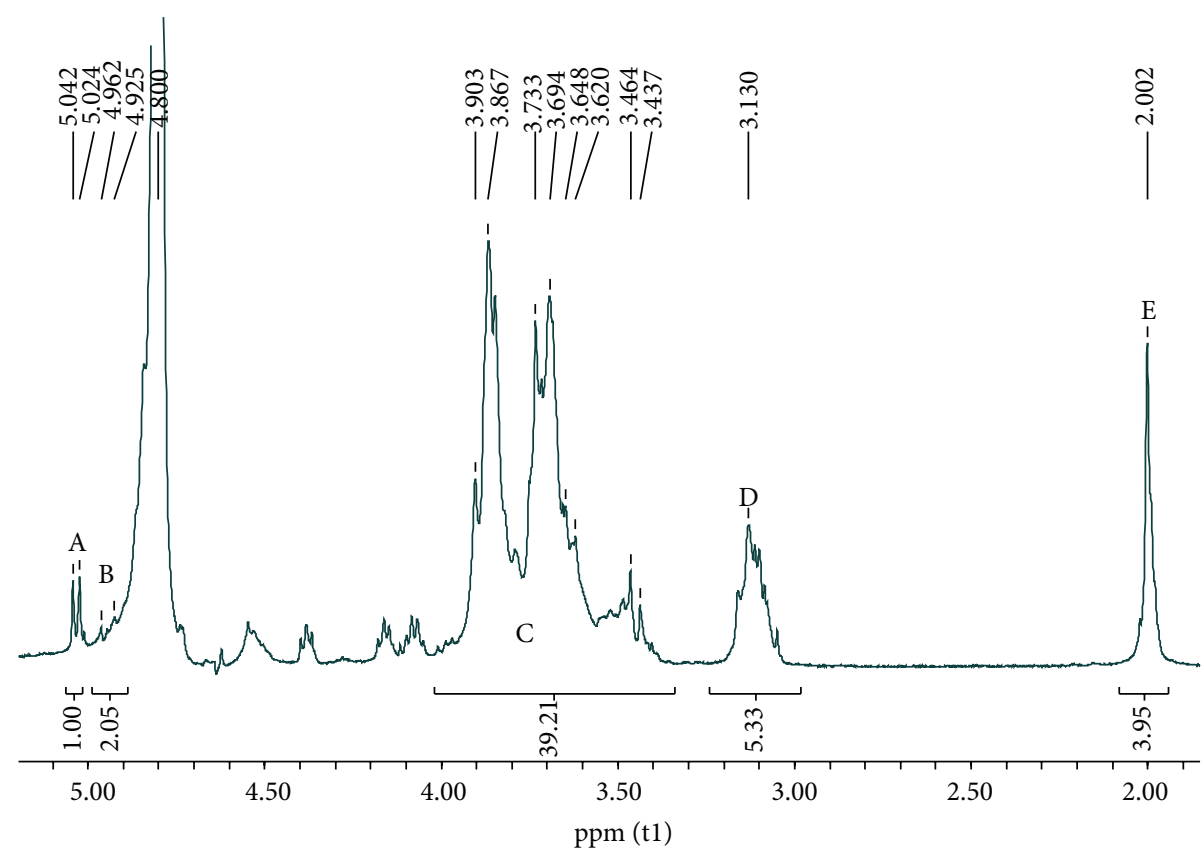

(a)

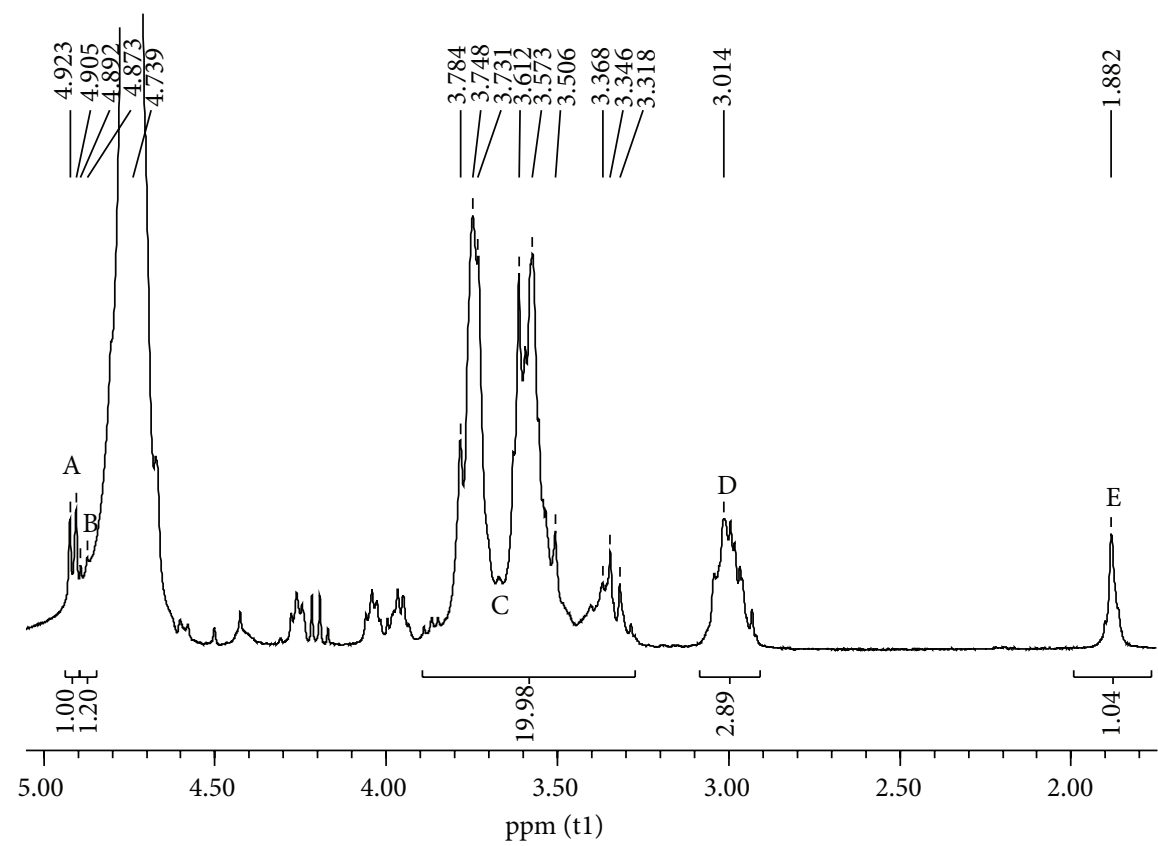

(b)

FIgURE 4: : ${ }^{1} \mathrm{H}$ NMR spectra of control chitosan sample A (a) and chitosan sample C (b), thermally treated at $100^{\circ} \mathrm{C}$ for $10 \mathrm{~h}$.

$3\left(0.33 \mathrm{~mol} \mathrm{dm}^{-3}\right.$ of acetic acid and $0.3 \mathrm{~mol} \mathrm{dm} \mathrm{m}^{-3}$ of sodium chloride) as described by Roberts [8]. From the linear regressions of control chitosan (A) using solvents (1), (2), and (3) were calculated intrinsic viscosities and Mv values using the Mark-Houwink-Kuhn-Sakurada equation, 1,254,259 $\mathrm{g} \mathrm{mol}^{-1}$, $121,048 \mathrm{~g} \mathrm{~mol}^{-1}$, and 193,400 $\mathrm{g} \mathrm{mol}^{-1}$, respectively. (For linear regressions, see Supplementary Figure 3S.)

The strong effects of the three different solvents were shown to be significant $(P \leq 0.05)$ when used for determination of viscosity average molar mass. The Mv value of chitosan (A) determined in solvent $1\left(0.2 \mathrm{~mol} \mathrm{dm}^{-3}\right.$ of acetic acid, $0.1 \mathrm{~mol} \mathrm{dm}^{-3}$ of sodium chloride, and $4 \mathrm{~mol} \mathrm{dm}^{-3}$ of urea) was $1,254,259 \mathrm{~g} \mathrm{~mol}^{-1}$, in solvent $2\left(0.1 \mathrm{~mol} \mathrm{dm}^{-3}\right.$ of acetic acid and $0.2 \mathrm{~mol} \mathrm{dm}^{-3}$ of sodium chloride) was $121,048 \mathrm{~g} \mathrm{~mol}^{-1}$, and in solvent $3\left(0.33 \mathrm{~mol} \mathrm{dm}^{-3}\right.$ of acetic acid and $0.3 \mathrm{~mol} \mathrm{dm}^{-3}$ of sodium chloride) was $193,400 \mathrm{~g} \mathrm{~mol}^{-1}$. Several set values for $K$ and $a$ of chitosan have been proposed in the literature [8]. The $K$-values depend on the average molar mass used and on the molar mass distribution of the samples [38]. The polydispersity index of sample A 
TABLE 4: Average molar mass (Mw), degree of polymerization, kinematic and apparent viscosties and viscosity average molar mass $(\mathrm{Mv})$ of chitosans obtained by thermal treatment and alkaline deacetylation.

\begin{tabular}{lccccc}
\hline Code & $\begin{array}{c}\mathrm{GPC}^{1} \\
\mathrm{Mw} \\
\left(\mathrm{g} \mathrm{mol}^{-1}\right)\end{array}$ & $\mathrm{DP}^{2}$ & $\begin{array}{c}\text { Apparent } \\
\text { viscosity } \\
(\mathrm{mPa} \cdot \mathrm{s})\end{array}$ & $\begin{array}{c}\text { Kinematic } \\
\text { viscosity } \\
(\mathrm{cSt})\end{array}$ & $\begin{array}{c}\text { Intrinsic } \\
\text { viscosity } \\
\mathrm{Mv} \\
\left(\mathrm{g} \mathrm{mol}^{-1}\right)\end{array}$ \\
\hline A & 235,000 & 1,383 & 29.9 & 13.9 & 193,400 \\
B & 62,500 & 366 & 2.3 & 1.9 & 93,594 \\
C & 7,700 & 45 & 1.4 & 1.2 & 10,978 \\
D & 193,000 & 1,171 & 4.9 & 5.1 & 30,219 \\
E & 184,000 & 1,089 & 4.7 & 5.2 & 91,203 \\
\hline
\end{tabular}

${ }^{1}$ Gel permeation chromatography. ${ }^{2}$ Degree of polymerization [DP = $\left.\mathrm{Mw} /\left(203 \times F_{\mathrm{A}}+161 \times\left(1-F_{\mathrm{A}}\right)\right)\right] .{ }^{3}$ Brookfield rheometer. ${ }^{4}$ Cannon-Fenske no. 200 viscometer. ${ }^{5}$ Ubbelohde type 53110/I Schott $\mathrm{GmbH}$ viscometer.

determined by GPC was 6.97, and for this reason different values of $\mathrm{Mv}$ were found for different $K$-values and solvents. By GPC analysis the average molar mass of chitosan A was $235,000 \mathrm{~g} \mathrm{~mol}^{-1}$, of the closest value to the Mv determined by viscosity (value $193,400 \mathrm{~g} \mathrm{~mol}^{-1}$ ) in solvent 3 . The same was observed for samples B, C, D, and E, indicating that $0.33 \mathrm{~mol} \mathrm{dm}^{-3}$ of acetic acid and $0.3 \mathrm{~mol} \mathrm{dm}{ }^{-3}$ of sodium chloride were the most suitable solvents for this determination.

The relationship between $\mathrm{Mv}$ and intrinsic viscosity $\eta_{i}$ is expressed by the Mark-Houwink-Kuhn-Sakurada equation, $\eta_{i}=\mathrm{kM}^{a}$, where the viscosity parameters $K$ and $a$ depend on the polymer, the temperature, the solvent, and the salt concentrations [1]. Different values of $\mathrm{Mv}$ were obtained by intrinsic viscosity $\eta_{i}$ for chitosan sample A using three different solvents by the high polydispersity index of raw material (6.97) calculated by GPC. Roberts [8] reports different ranges of $\mathrm{Mv}$ for different solvents (Table 2). Chitosan samples with a high polydispersity index (6.97), whose average molar masses were determined by viscometry, showed very large discrepancies; however for chitosans with a low polydispersity index there was no discrepancy of average molar masses obtained by viscometry.

It was observed that methods used to characterize thermally treated chitosan samples and chitosan samples obtained by alkaline deacetylation showed a good correlation between parameter values analyzed to determine molar masses and viscosities. Of these three methods, GPC and apparent and kinematic viscosities cited and discussed as well as intrinsic viscosity used in the determination of $\mathrm{Mv}$, intrinsic viscosity was shown to be reliable and efficient, since it can be closely correlated to the average $\mathrm{Mw}$ obtained by GPC (Figure 1(b)).

In Table 4 the average molar masses, degrees of polymerization, apparent and kinematic viscosities, and viscosity average molar masses of chitosan obtained by thermal treatment and alkaline deacetylation are described.

In Table $2 \mathrm{~S}$ the observed decrease in $\mathrm{Mw}$ (GPC), Mv (intrinsic viscosity), and apparent and kinematic viscosities
TABLE 5: Degree of acetylation of chitosan samples determined by potentiometric titration and ${ }^{1} \mathrm{H}$ NMR.

\begin{tabular}{lcc}
\hline Code & \multicolumn{1}{c}{$F_{\mathrm{A}}$} & $\mathrm{NMR}^{2}$ \\
\hline $\mathrm{A}$ & $\mathrm{PT}^{1}$ & 0.22 \\
$\mathrm{~B}$ & 0.21 & $\mathrm{nd}$ \\
$\mathrm{C}$ & 0.23 & 0.22 \\
$\mathrm{D}$ & 0.27 & 0.08 \\
$\mathrm{E}$ & 0.09 & 0.16 \\
\hline${ }^{1}$ Potentiometric titration. ${ }^{2}$ Nuclear magnetic resonance. nd: not determined.
\end{tabular}

of chitosans thermally degraded at $100^{\circ} \mathrm{C}$ for 3 and $10 \mathrm{~h}$ is described.

Determination of the molar mass by viscometry is useful to compare modifications of chitosan average molar mass but not to determine the absolute molar mass. In the present study, it was possible to verify the average molar masses calculated by more than one technique and to compare the viscometry method with gel permeation chromatography. GPC offers the possibility to obtain the molar mass distribution and its polydispersity. Comparing the decrease (\%) in the values of parameters Mw, Mv, apparent viscosity, and kinematic viscosity after $3 \mathrm{~h}$ of thermal treatment, it can be observed that the techniques used to evaluate thermal degradation gave different values. But in comparing the same parameters after $10 \mathrm{~h}$ of thermal treatment, it was observed that the techniques gave similar values (Table $2 S$ ). Differences observed by techniques used in this study to evaluate the process of depolymerization of chitosan can be explained by the different polydispersity indices determined by GPC after $3 \mathrm{~h}$ (4.24) and after $10 \mathrm{~h}$ (1.33) of thermal treatment. The polydispersity index of chitosans treated for $3 \mathrm{~h}$ was shown to be about three times larger than that of chitosans treated for $10 \mathrm{~h}$. The polydispersity index and molar mass distribution can affect the results of the methods used to determine the molar mass of chitosan samples.

\subsection{Determination of Mole Fraction of N-Acetylglucosamine} Residues in Chitosan. Initially, it was also our goal to compare two analytical methods to determine mole fraction of $\mathrm{N}$ acetylglucosamine residues in chitosans. The most commonly applied methods for determination of the $F_{\mathrm{A}}$ in chitin and chitosan are infrared (IR), crosspolarization/magic angle spinning nuclear magnetic resonance (CP/MAS $\left.{ }^{13} \mathrm{C}-\mathrm{NMR}\right)$, first-derivative UV and $\mathrm{CD}$ spectroscopy, potentiometric and dye adsorption titration, pyrolysis-gas chromatography, quantification of acetic acid in hydrolysates by liquid chromatography, and thermal and elemental analysis [1]. The potentiometric titration method and the ${ }^{1} \mathrm{H}$ NMR were chosen for the study of their ability to determine the acetyl group fraction of our group of chitosans (Table 5). Titration was chosen because it is a very simple and inexpensive analytical procedure and ${ }^{1} \mathrm{H}$ NMR because it is one of the most cited tools currently used for this task.

Another goal of this present work was to verify the effect of the heating on the degree of acetylation of chitosans. The 
same group of chitosan samples which had been previously analyzed for average $\mathrm{Mw}$ was also analyzed for $F_{\mathrm{A}}$.

It was observed that the thermal treatment used to depolymerize chitosans did not seem to significantly affect the $F_{\mathrm{A}}$ of the chitosan samples, when determined either by titration or by ${ }^{1} \mathrm{H}$ NMR (Table 5). Figures 4(a) and 4(b) show ${ }^{1} \mathrm{H}$ NMR spectra of chitosan samples $\mathrm{A}$ and C. $F_{\mathrm{A}}$ of control chitosan (A) and chitosan thermally treated for $10 \mathrm{~h}(\mathrm{C})$ was 0.22 and 0.22 , respectively, as determined by ${ }^{1} \mathrm{H}$ NMR, and 0.21 and 0.27 , respectively, as determined by PT. Thus, thermal treatment of chitosan at $100^{\circ} \mathrm{C}$ for $10 \mathrm{~h}$ has very little or even no ability to modify the glucosamine bonds.

The $F_{\mathrm{A}}$ value obtained by the titration method is precise when some steps are taken to standardize the $\mathrm{HCl}$ and $\mathrm{NaOH}$ solutions and filtrate the chitosan hydrochloride solution to avoid mistakes when chitosan samples are partially soluble. Raymond et al. [33] observed that titration of chitosan is useful for analysis of low $F_{\mathrm{A}}$ samples. In our study the range of $F_{\mathrm{A}}$ samples was 0.08 to 0.22 and the accuracy of the ${ }^{1} \mathrm{H}$ NMR and PT methods in determining $F_{\mathrm{A}}$ did not differ.

The chitosan samples characterized in this work were used to evaluate barrier properties of chitosan films, whose water permeability of chitosan films is $50 \%$ reduced when molar mass of the original chitosan is reduced from $235 \mathrm{kDa}$ (DP 1,383 ) to approximately $13.7 \mathrm{kDa}$ (DP 45), [39] and antifungal activities in filamentous fungi, whose chitosan samples with low molar masses were more effective [40].

\section{Conclusions}

This study showed that thermal treatment results in chitosans with different molar masses but the same degree of acetylation, as determined by ${ }^{1} \mathrm{H}$ NMR spectroscopy and potentiometric titration. The process of thermal depolymerization under the conditions used in this study was shown to be appropriate for obtaining chitosans with smaller molar masses, given that in this process strong hydrolytic reagents, such as hydrochloric, sulfuric, and phosphoric acids, are not used. However, the lost of insoluble particles, $2 \%$ and $6 \%$ $(\mathrm{m} / \mathrm{m})$ in thermally treated chitosans for 3 and $10 \mathrm{~h}$, respectively, were observed. The variables used to characterize the depolymerization process showed a good correlation. Six hours of thermal treatment was sufficient to obtain chitosans with a molar mass $90 \%$ smaller than that of the control chitosan without treatment.

\section{Nomenclature}

AV: Apparent viscosity mPas

$F_{\mathrm{A}}$ : Mole fraction of $\mathrm{N}$-acetylglucosamine residues (-)

DR: Depolymerization rate $\% \mathrm{~h}^{-1}$

$\mathrm{KV}$ : Kinematic viscosity cSt

$\mathrm{Mv}$ : Viscosity average molar mass $\mathrm{g} \mathrm{mol}^{-1}$

Mw: Mass average of molar mass (determined by GPC) $\mathrm{g} \mathrm{mol}^{-1}$

$C$ : Concentration of chitosan solution $\mathrm{g} \mathrm{dm}^{-3}$

$m_{0}$ : Mass of dry filter $\mathrm{g}$

$m_{1}$ : Mass of chitosan sample $\mathrm{g}$ $m_{2}$ : $\quad$ Mass of filter containing insoluble particles after drying $g$

$t_{1}$ : $\quad$ Flow time for the chitosan solution $\mathrm{s}$

$t_{0}$ : $\quad$ Flow time for the solvent system $\mathrm{s}$

$K: \quad$ Mark-Houwink constant $\mathrm{dm}^{3} \mathrm{~g}^{-1}$

A: $\quad$ Mark-Houwink constant (-)

$m_{\mathrm{ch}}$ : Chitosan sample mass g

$M_{\mathrm{ch}}$ : Molar mass of glucosamine unit $161 \mathrm{~g} \mathrm{~mol}^{-1}$

$V_{\mathrm{NaOH}}$ : Volume of $\mathrm{NaOH}$ solution $\mathrm{cm}^{3}$

$M_{\mathrm{NaOH}}$ : Molar concentration of $\mathrm{NaOH}$ solution mol dm ${ }^{-3}$

PT: $\quad$ Potentiometric titration (-).

\section{Greek Letters}

$\eta_{i}:$ Intrinsic viscosity $\mathrm{dm}^{3} \mathrm{~g}^{-1}$

$\eta_{L}$ : Limiting viscosity number $\mathrm{dm}^{3} \mathrm{~g}^{-1}$.

\section{Conflict of Interests}

The authors declare that there is no conflict of interests regarding the publication of this paper.

\section{Acknowledgments}

Financial support by the Brazilian funding agencies FAPESP, CAPES, and CNPq is gratefully acknowledged. Thanks also are due to the PROBRAL Programme (CAPES/DAAD) and to the European Commission (ALFA Programme, II-0259FA-FC POLYLIFE).

\section{References}

[1] M. G. Peter, Chitin and Chitosan from Fungi, edited by A. Steinbüchel, chapter 5, Wiley-VCH, Weinheim, Germany, 2002.

[2] M. G. Peter, Chitin and Chitosan from Animal Sources, chapter 6, Wiley-VCH, Weinheim, Germany, 2002, edited by A. Steinbüchel.

[3] E. N. Oliveira Jr., Tese de Doutorado, Universidade Estadual de Campinas, São Paulo, Brazil, 2006.

[4] E. N. Oliveira Jr., N. E. El Gueddari, B. M. Moerschbacher, M. G. Peter, and T. T. Franco, "Growth of phytopathogenic fungi in the presence of partially acetylated chitooligosaccharides," Mycopathologia, vol. 166, no. 3, pp. 163-174, 2008.

[5] E. A. El Gaouth, J. Arul, J. Grenier, and A. Asselin, "Antifungal activity of chitosan on two postharvest pathogens of strawberry fruits," Phytopathology, vol. 82, pp. 398-402, 1992.

[6] H. K. No, N. Y. Park, S. H. Lee, and S. P. Meyers, "Antibacterial activity of chitosans and chitosan oligomers with different molecular weights," International Journal of Food Microbiology, vol. 74, no. 1-2, pp. 65-72, 2002.

[7] H. K. Holme, H. Foros, H. Pettersen, M. Dornish, and O. Smidsrød, "Thermal depolymerization of chitosan chloride," Carbohydrate Polymers, vol. 46, no. 3, pp. 287-294, 2001.

[8] G. A. F. Roberts, Chitin Chemistry, Houndmills MacMillan Press, New York, NY, USA, 1st edition, 1992. 
[9] S. T. Horowitz, S. Roseman, and H. J. Blumenthal, "The preparation of glucosamine oligosaccharides. I. Separation," Journal of the American Chemical Society, vol. 79, no. 18, pp. 50465049, 1957.

[10] J. A. Rupley, "The hydrolysis of chitin by concentrated hydrochloric acid, and the preparation of low-molecular-weight substrate for lysozyme," Biochimica et Biophysica Acta, vol. 83, pp. 245-255, 1964.

[11] P. R. Rege and L. H. Block, "Chitosan processing: Influence of process parameters during acidic and alkaline hydrolysis and effect of the processing sequence on the resultant chitosan's properties," Carbohydrate Research, vol. 321, no. 3-4, pp. 235$245,1999$.

[12] M.-Y. Lee, F. Var, Y. Shin-ya, T. Kajiuchi, and J.-W. Yang, "Optimum conditions for the precipitation of chitosan oligomers with DP 5-7 in concentrated hydrochloric acid at low temperature," Process Biochemistry, vol. 34, no. 5, pp. 493-500, 1999.

[13] K. M. Vårum, M. H. Ottoy, and O. Smidsød, "Acid hydrolysis of chitosans," Carbohydrate Polymers, vol. 46, no. 1, pp. 89-98, 2001.

[14] M. Hasegawa, A. Isogai, and F. Onabe, "Preparation of lowmolecular-weight chitosan using phosphoric acid," Carbohydrate Polymers, vol. 20, no. 4, pp. 279-283, 1993.

[15] Z. Jia and D. Shen, "Effect of reaction temperature and reaction time on the preparation of low-molecular-weight chitosan using phosphoric acid," Carbohydrate Polymers, vol. 49, no. 4, pp. 393396, 2002.

[16] D. Schanzenbach, C. Matern, and M. G. Peter, Cleavage of Chitin by Means of Sulfuric Acid/Acidic Anhydride, Atec, Grottammare, Italy, 1997.

[17] G. G. Allan and M. Peyron, "Molecular weight manipulation of chitosan I: kinetics of depolymerization by nitrous acid," Carbohydrate Research, vol. 277, no. 2, pp. 257-272, 1995.

[18] C. Bosso, J. Defaye, A. Domard, A. Gadelle, and C. Pedersen, "The behavior of chitin towards anhydrous hydrogen fluoride. Preparation of $\beta$ - $(1 \rightarrow 4)$-linked 2-acetamido-2-deoxy-d-glucopyranosyl oligosaccharides," Carbohydrate Research, vol. 156, pp. 57-68, 1986.

[19] M. Dixon and E. C. Webb, Enzymes, Longman Group Limited, New York, NY, USA, 1979.

[20] S. Aiba, "Preparation of $N$-acetylchitooligosaccharides by hydrolysis of chitosan with chitinase followed by $\mathrm{N}$-acetylation," Carbohydrate Research, vol. 265, no. 2, pp. 323-328, 1994.

[21] I. A. Stoyachenko, V. P. Varlamov, and V. A. Davankov, "Chitinases of Streptomyces kurssanovii: purification and some properties," Carbohydrate Polymers, vol. 24, no. 1, pp. 47-54, 1994.

[22] M. Izume and A. Ohtakara, "Preparation of D-glucosamine oligosaccharides by the enzymatic hydrolysis of chitosan," Agricultural and Biological Chemistry, vol. 51, no. 4, pp. 11891191, 1987.

[23] D. M. Fenton and D. E. Eveleigh, "Purification and mode of action of a chitosanase from Penicillium islandicum," Journal of General Microbiology, vol. 126, no. 1, pp. 151-165, 1981.

[24] I. G. Alonso, C. Peniche-Covas, and J. M. Nieto, "Determination of the degree of acetylation of chitin and chitosan by thermal analysis," Journal of Thermal Analysis, vol. 28, no. 1, pp. 189-193, 1983.

[25] P. Köll, G. Borchers, and J. O. Metzger, "Thermal degradation of chitin and cellulose," Journal of Analytical and Applied Pyrolysis, vol. 19, pp. 119-129, 1991.
[26] C. Peniche-Covas, W. Argülles-Monal, and J. A. San Romàn, "A kinetic study of the thermal degradation of chitosan and a mercaptan derivative of chitosan," Polymer Degradation and Stability, vol. 39, no. 1, pp. 21-28, 1993.

[27] M. Mucha and A. Pawlak, "Thermal analysis of chitosan and its blends," Thermochimica Acta, vol. 427, no. 1-2, pp. 69-76, 2005.

[28] J. Zawadzki and H. Kaczmarek, "Thermal treatment of chitosan in various conditions," Carbohydrate Polymers, vol. 80, no. 2, pp. 394-400, 2010.

[29] D. de Britto and S. P. Campana-Filho, "Kinetics of the thermal degradation of chitosan," Thermochimica Acta, vol. 465, no. 1-2, pp. 73-82, 2007.

[30] T. Sannan, K. Kurita, and Y. Iwakura, "Studies on chitin. V. Kinetics of deacetylation reaction," Polymer Journal, vol. 9, no. 6, pp. 649-651, 1977.

[31] T. G. Liu, B. Li, W. Huang et al., "Effects and kinetics of a novel temperature cycling treatment on the $\mathrm{N}$-deacetylation of chitin in alkaline solution," Carbohydrate Polymers, vol. 77, no. 1, pp. 110-117, 2009.

[32] K. M. N. D. C. Canella and R. B. Garcia, "Caracterização de quitosana por Cromatografia de Permeação em Gel-Influência do método de preparação e do solvente," Quimica Nova, vol. 24, no. 1, pp. 13-17, 2001.

[33] L. Raymond, F. G. Morin, and R. H. Marchessault, "Degree of deacetylation of chitosan using conductometric titration and solid-state NMR," Carbohydrate Research, vol. 246, pp. 331-336, 1993.

[34] K. M. Vårum, M. W. Anthonsen, H. Grasdalen, and O. Smidsrød, "Determination of the degree of $\mathrm{N}$-acetylation and the distribution of $N$-acetyl groups in partially $N$-deacetylated chitins (chitosans) by high-field n.m.r. spectroscopy," Carbohydrate Research, vol. 211, no. 1, pp. 17-23, 1991.

[35] M. Terbojevich and A. Cosani, Molar Mass Determination of Chitin and Chitosan, edited by R. A. A. Muzzarelli and M. G. Peter, Atec, Grottammare, Italy, 1997.

[36] G. A. F. Roberts and K. E. Taylor, "Chitosan gels, 3. The formation of gels by reaction of chitosan with glutaraldehyde," Die Makromolekulare Chemie, vol. 190, no. 5, pp. 951-960, 1989.

[37] J. N. BeMiller, Acid-Catalysed Hydrolysis of Glycosides, Academic Press, New York, NY, USA, 1967.

[38] M. H. Ottøy, K. M. Vårum, B. E. Christensen, M. W. Anthonsen, and O. Smidsrød, "Preparative and analytical size-exclusion chromatography of chitosans," Carbohydrate Polymers, vol. 31, no. 4, pp. 253-261, 1996.

[39] C. M. P. Yoshida, E. N. Oliveira Jr., and T. T. Franco, "Chitosan tailor-made films: the effects of additives on barrier and mechanical properties," Packaging Technology and Science, vol. 22, no. 3, pp. 161-170, 2009.

[40] E. N. Oliveira Junior, N. E. El Gueddari, B. M. Moerschbacher, and T. T. Franco, "Growth rate inhibition of phytopathogenic fungi by characterized chitosans," Brazilian Journal of Microbiology, vol. 43, no. 2, pp. 800-809, 2012. 

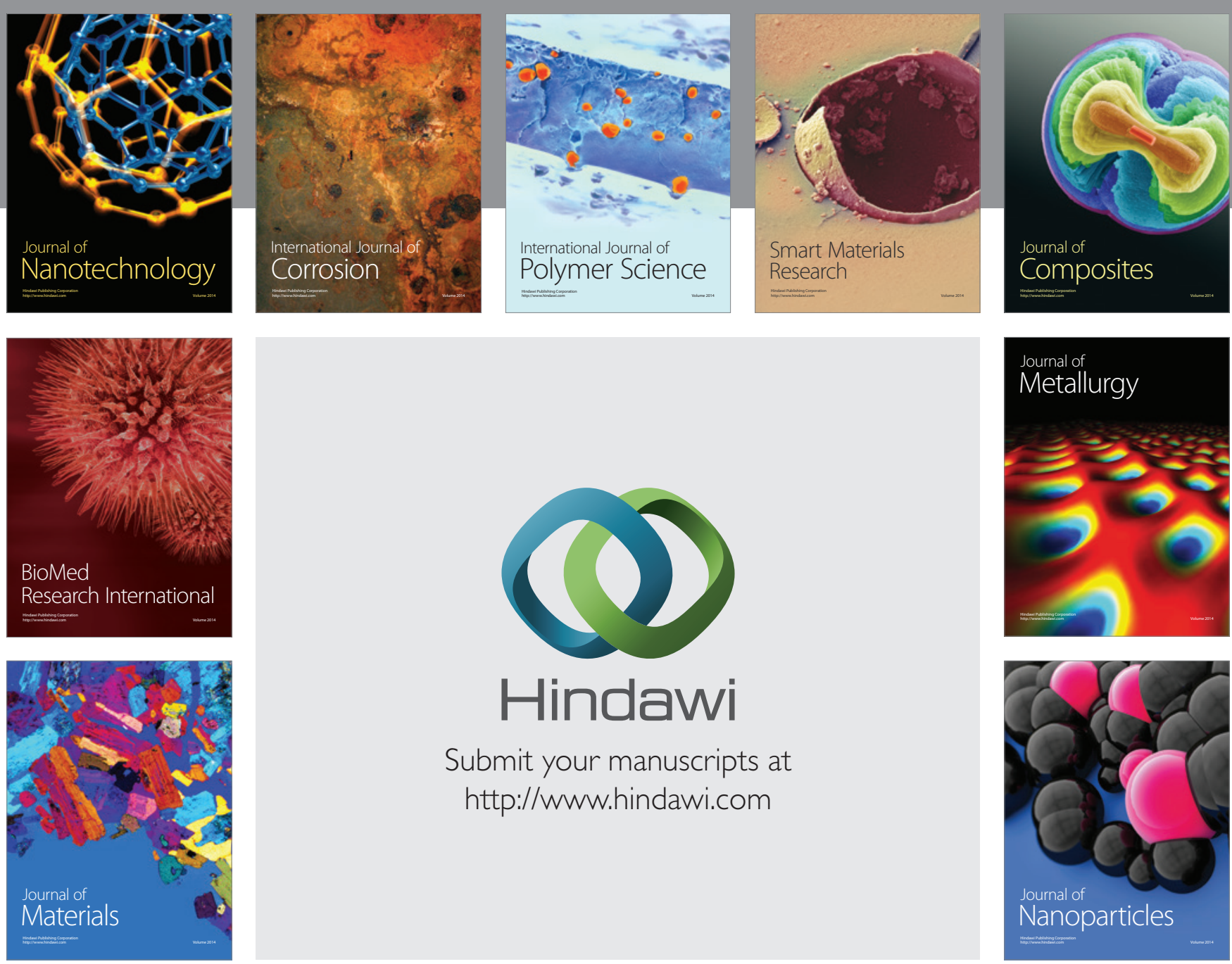

Submit your manuscripts at http://www.hindawi.com
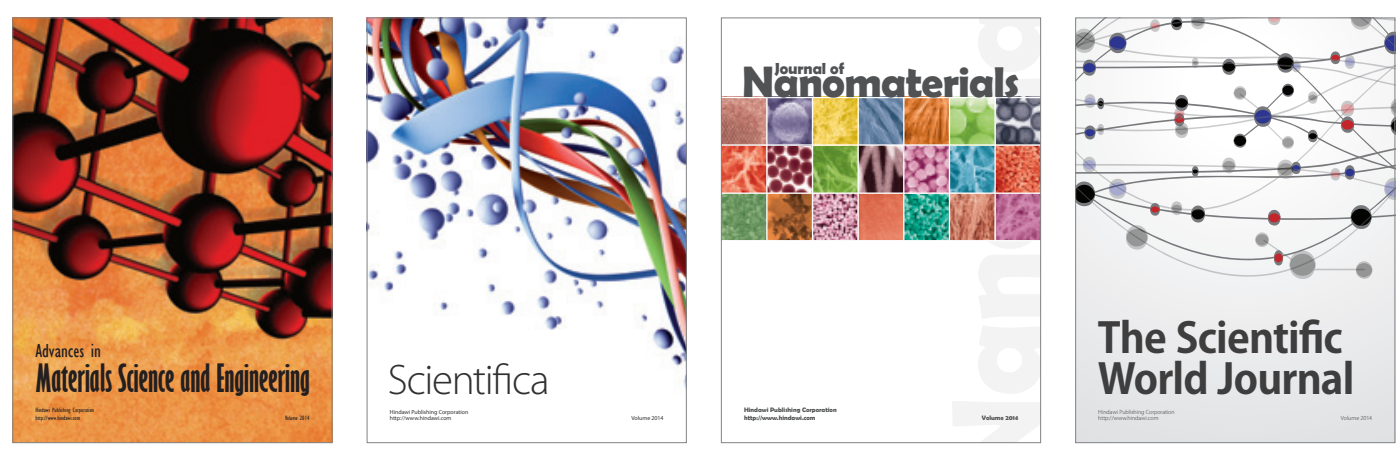

\section{The Scientific World Journal}
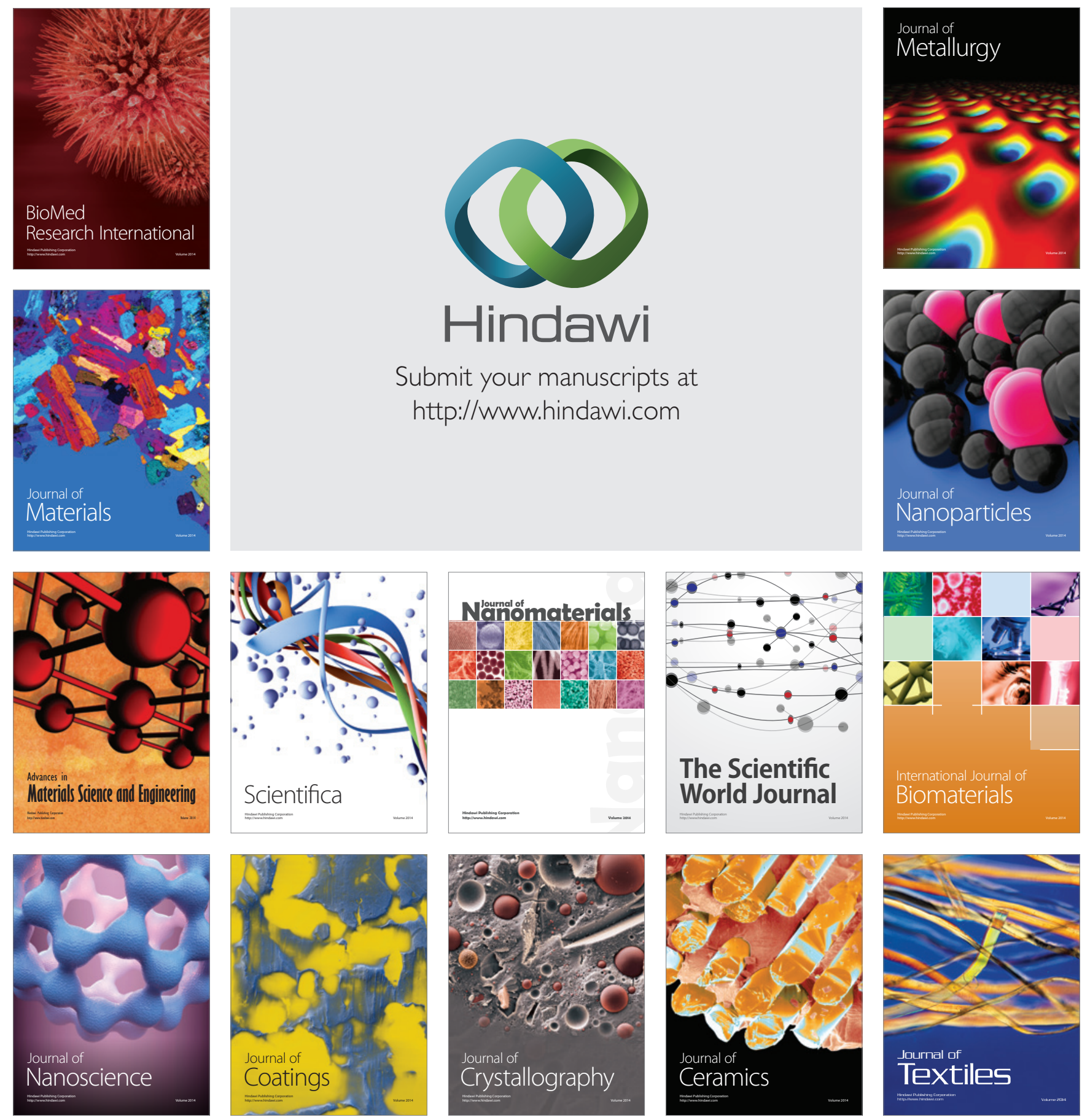